\title{
FEMINIZACIÓN DE LA LENGUA Y LENGUAJE INCLUSIVO. UNA MIRADA INTERDISCIPLINARIA
}

\author{
LANGUAGE FEMINIZATION AND INCLUSIVE LANGUAGE. \\ AN INTER-DISCIPLINARY APPROACH
}

\author{
GERARDO ÁLVAREZ ${ }^{*}$ ANDREA ÁLVAREZ DÍAZ**
}

Resumen: El texto analiza desde un abordaje lingüístico, la controversial propuesta del lenguaje inclusivo y las implicaciones de su eventual uso en el idioma castellano. Reconociendo el significativo aporte de las reivindicaciones del movimiento feminista en la obtención de derechos sociales, políticos y económicos para las mujeres, se pondera la demanda de modificación del lenguaje en función de distintos elementos de la arquitectura del idioma: el género gramatical, la coherencia textual y la progresión textual. Con todo, se trata en nuestra opinión, de una discusión abierta que requiere de propuestas encaminadas a la real modificación de las relaciones de poder entre hombres y mujeres.

PAlabras ClAVE: Lenguaje inclusivo, género gramatical, progresión textual, coherencia textual, feminismo.

AвSTRACT: This text analyzes from a linguistic approach, the controversial proposal of inclusive language and the implications of its eventual use in the Spanish language. Recognizing the significant contribution of the feminist movement's demands in obtaining social, political and economic rights for women, the need to modify language is weighed based on different elements of language architecture: grammatical gender, textual coherence and textual progression. However, in our opinion, this is an open discussion that requires proposals aimed at the real modification of the power relations between men and women.

Keywords: Inclusive Language, Grammatical Gender, Textual Progression, Textual Coherence, Feminism.

\footnotetext{
* Doctor en Lingüística. Académico jubilado de la Universidad de Concepción. Buin, Chile. Correo electrónico: geralvar@gmail.com

** Doctora en Antropología Social. Miembro del Grupo de Investigación Interdisciplinario en Género y académica de la Universidad de Tarapacá, Iquique, Chile. Correo electrónico: aalvarez@uta.cl. Orcid: https://orcid.org/0000-0002-7244-3690
} 


\section{INTRODUCCIÓN}

T A APARICIÓN DE LA mujer en el universo discursivo político es un fennómeno relativamente reciente. Digamos, dos siglos. Anteriormente, durante el feudalismo la mujer no existe como sujeto político. Este estado de cosas comienza a cambiar con la introducción de la modernidad capitalista (Hobsbawn, 2006). Es instructivo hacer notar, por ejemplo, que en el evento que marcó el inicio de la Revolución Francesa de 1789 -la convocación por Luis XVI a los Estados generales- no aparece ninguna mujer en la nómina de los 1200 delegados. La razón es simple: durante el feudalismo, la mujer no es ciudadana. Como tampoco lo son los miembros del Estado llano que no están inscritos en el rol de Contribuyentes. Para democratizar el derecho a voto, la Revolución proclamó el sufragio universal para elegir a los miembros de la Convención que habría de dotar a Francia de una Constitución (Labrune y Toutain, 1986). Pero ese "sufragio universal" no incluía a las mujeres. El "universo" de la época solo refería a los hombres. Pero ya hubo voces femeninas, como la de Olympe de Gouges, que se levantaron para hacer ver que la Revolución había olvidado los derechos de la mujer. Mme. De Gouges, autora de la Declaración de los derechos de la mujer y de la ciudadana, murió en la guillotina en 1793 (Cano, 1990).

Hay que mencionar también, siempre en Francia, que las revoluciones de 1830 y de 1848, y sobre todo la Revolución de la Comuna de París (1872), ya muestran a las mujeres interviniendo codo a codo con los hombres en el intento de abrir paso a un nuevo orden social. Notable es, por ejemplo, el rol de Louise Michel en esa insurrección. Pero habrá que esperar más de un siglo y medio hasta que por fin se reconozca en Francia, en 1945, el derecho a voto de las mujeres (Labrune y Toutain, 1986).

En Chile, la lucha de las sufragistas aparece desde comienzos del siglo XX. En 1934 se obtiene el derecho a voto de las mujeres en las elecciones municipales. Pero para obtener el pleno derecho a voto habrá que esperar hasta la década de los 40. En efecto, la Constitución de 1925 señalaba, formalmente, en su Artículo $7^{\circ}$ : "Son ciudadanos con derecho a sufragio los chilenos que hayan cumplido 21 años y que sepan leer y escribir". Pero el significado "neutro" del sintagma "los chilenos" no fue entendido cabalmente, y de hecho no se permitía a las mujeres inscribirse en los registros electorales nacionales. (En verdad, la discusión venía desde la propia Constitución de 1833). En 1947, durante la presidencia de González Videla se logró un acuerdo para crear la figura legal del "Registro electoral de varones" y "Registro electoral de mujeres", y la nueva ley se aplica desde la 
votación del año 1952 (Álvarez y Vilches, 2019; López Varas y Gamboa Valenzuela, 2015). En los hechos, se adoptó una solución consensuada: en la Constitución rige el carácter inclusivo del artículo "los", y en la legislación se establecen los mecanismos para cada grupo específico; es decir, mujeres y hombres.

En lo que a nosotros concierne en este trabajo, este debate revela que por un largo tiempo las mujeres han tenido que enfrentarse con un fenómeno oculto de la lengua, del dominio de las categorías gramaticales. En efecto, categorías como el género gramatical están estructuradas, desde los orígenes del español a partir del "latín vulgar" -es decir desde hace unos 15 siglos- en una forma binaria que podemos llamar asimétrica: una forma femenina (la) y una forma masculina (el), la que también asume una función de determinante inclusivo cuando la cuestión de género no es pertinente. Y como todas las cosas en materia de lenguaje, esa pertinencia o no-pertinencia de la distinción de género depende de la intención del sujeto enunciador. Por ejemplo, un enunciador puede decir "Los chilenos comen empanadas" entendiendo con esa expresión que ella se aplica tanto a los hombres chilenos como a las mujeres chilenas, y que él estima que en este caso la distinción de género no es pertinente. En cambio, si el mismo hablante dice algo como "Las chilenas se visten muy bien", está diciendo -sin necesidad de decirlo- que solo está hablando de las mujeres. Volveremos más adelante sobre esta noción.

\section{LA FEMINIZACIÓN DE LAS PROFESIONES}

Durante el mismo período - primera mitad del siglo XIX- empieza a producirse el fenómeno social de la irrupción de las mujeres en el mundo del trabajo profesional. Efectivamente, la primera mujer que se gradúa de ingeniero es Justicia Acuña, en 1919 (Baros, 2020), mientras la primera mujer graduada en Medicina fue Eloísa Díaz en el año 1887 (Salas et al., 2019).

Este fenómeno del mundo social introduce, en el orden del lenguaje, el problema de la denominación de estas profesionales, problema que se puede llamar menor, porque la estructura del español ya permite -desde muy antiguo- la distinción 'masculino/femenino' en las profesiones, como lo encontramos, por ejemplo, en El Libro de Buen Amor, del Arcipreste de Hita [1330-1343]. Distinciones de género, como: "pastor/pastora", aldeano/ aldeana", "labriego/labriega", son absolutamente normales desde la lengua española medieval. Por lo tanto, denominaciones como "ingeniera", "abo- 
gada", "doctora” no debieran suscitar ningún problema de orden lingüístico. La dificultad pareciera venir más de una resistencia del cuerpo social que todavía parece no acomodarse al hecho de que haya mujeres que ocupen determinados cargos (o profesiones "liberales"). Uno de esos campos parece ser la función militar: "una oficiala", "una generala", "una mayora" aparecen como no aceptables. Otro campo social parece ser la diplomacia: nos informan que se sigue hablando de "primer secretario", "segundo secretario", "tercer secretario", aunque el secretario en cuestión sea "una secretaria".

Dicho desde ya, en términos precisos: en muchos casos la resistencia al cambio no es "culpa del lenguaje" sino de la institución social. Otras veces la forma femenina "parece disonante", "extraña", "fea": ¿se puede decir "una miembra de la Academia"? ¿"una pilota” de LAN Chile? Suena mal, es cierto. Y se producen excesos, sin duda. Quizás en esos casos existe el recurso de la perífrasis: "La doctora Pérez es miembro de la Orden de los médicos de Chile".

Un segundo momento, más reciente, en esta reivindicación feminista es la exigencia de la "feminización de la lengua", que va más allá de la simple denominación de las profesiones u oficios. Ahora se trata de una exigencia totalizante: es toda la producción, oral o escrita, la que tiene que "feminizarse". Rechazando la posibilidad de rol "neutro" de la marca masculina de género, ya no podrá más decirse "los chilenos". Habrá que repetir sistemáticamente: "los chilenos y las chilenas".

Esta exigencia lleva, en el nivel de la frase, a la producción de textos orales o escritos en los que todos los sintagmas nominales (con sus determinantes y sus adjetivos) deben duplicarse. Este fenómeno se encuentra, al comienzo, sobre todo en los discursos sindicalistas: "Los trabajadores y las trabajadores chilenos/chilenas están inquietos/inquietas... O bien: los/las trabajadores/trabajadoras, chilenos/chilenas están inquietos/inquietas... Así se ha extendido la exigencia de feminización de los substantivos mucho más allá de la denominación de las profesiones, cargos de representación u oficios: "Luego del accidente, los y las heridos y heridas fueron atendidos/ atendidas en el hospital". Aparecen así construcciones verbales que dificultan radicalmente los intercambios verbales, porque hacen laboriosa la comprensión oral o escrita, al obligar a repetir ad nauseam los diversos sintagmas.

Esta deformación del uso de la lengua ha llevado a diversos lingüistas a intervenir en el debate, para establecer algunos parámetros de discusión que vienen de la ciencia del lenguaje. 


\section{ALGUNAS OBSERVACIONES LINGÜÍSTICAS}

\section{El lenguaje y "la realidad"}

Una de las primeras observaciones advierte que las formas lingüísticas no deben confundirse con la realidad objetiva. No se deben confundir "las palabras" con "las cosas". Empezando por la simple denominación: no hay ninguna relación necesaria entre la palabra y la cosa designada. ¿Por qué el queso se llama así y no froste, norden, albera, o coltín? ¿Qué relación hay entre la palabra "queso" y el objeto "queso"? Ninguna, nos aclara el fundador de la lingüística moderna, el suizo Ferdinand de Saussure (1916) que introduce así la noción de "arbitrariedad del signo".

\section{Las distinciones gramaticales}

Un fenómeno similar ocurre con las categorías. La lengua "ordena" las palabras según ciertas categorías gramaticales, algunas universales, otras específicas de tal o cual lengua. Por ejemplo, para la noción de cantidad, las diversas lenguas distinguen entre "singular" y "plural", lo único y lo múltiple (p.e.: el libro, los libros). ¿Y si el hablante no quiere distinguir entre singular y plural y quiere, por ejemplo, hablar del libro en general? Nosotros, en español, cuando decimos "La feria del libro" es evidente que no estamos hablando de un solo libro. Pero usamos el singular, que incluye el plural, porque como se dice en lingüística el singular es "el caso no marcado de la categoría de número" (Ejemplo de Bernard Pottier, 1974).

En las distinciones binarias, el hecho de que uno de los términos de la oposición funcione como caso no marcado contribuye, en gran medida, a lo que se llama la economía de la lengua, es decir el sistema, el orden, de la lengua. Lo mismo ocurre con la categoría de género.

No confundir "sexo biológico" y "género gramatical"

En el caso de la distinción de "género gramatical", el latín distinguía tres posibilidades: masculino, femenino y neutro. Con el paso del latín a las lenguas llamadas romances (francés, español, portugués, rumano, italiano...) -tránsito que duró varios siglos- el neutro desapareció. Y todas las palabras se distribuyeron entre "masculino" y "femenino", de un modo ampliamente arbitrario. Esa arbitrariedad, típica de la categoría de género en las diver- 
sas lenguas, explica por qué, por ejemplo, el sol es masculino en algunas lenguas y femenino, en otras. Y lo mismo ocurre con "la luna", femenina o masculina según las lenguas.

Pero incluso en el caso de los referentes "sexuados", esta categorización gramatical de masculino/femenino no está regida necesariamente por la división "en la vida real" entre los sexos. Por ejemplo, si un periódico presenta un titular diciendo: "El Real Madrid nos visitará en junio con todas sus estrellas", todo lector entenderá que "las estrellas" -género femeninodesigna a personas que son hombres. Del mismo modo, se puede decir de un artista hombre que es "una vedette": "Lucho Gatica fue una gran vedette de la canción". Nótese, al pasar, que la palabra "artista" puede designar a un hombre, a pesar de su forma aparentemente femenina, como una gran cantidad de palabras que terminan en "a": dentista, socialista, especialista... (Ejemplo oído en la calle: Un hombre protesta a toda voz: "Yo soy la víctima y me quieren llevar preso").

Así, desde muy temprano -los años ' 80 - diversos lingüistas llaman la atención sobre la necesidad de respetar el lenguaje que no es, de ningún modo, el culpable de las injusticias que existen en el mundo real. El lenguaje es para el ser humano la más formidable herramienta de acción social, la que permite combatir, por ejemplo, las representaciones arcaicas (patriarcales, clasistas, colonialistas...) que pueden predominar en determinado conjunto social. El lenguaje es nuestro hogar común en el que todos nos reconocemos, el que contribuye desde que nacemos a construir nuestra identidad. Si destrozamos el lenguaje cortamos el puente que nos une con todos nuestros semejantes, en este caso, con aquellos con quienes queremos construir una sociedad más justa, más respetuosa, más igualitaria.

\section{El lenguaje "inclusivo"}

El movimiento feminista da un paso más - ahora asociado con el "movimiento de la diversidad sexual- cuando pretende imponer ya no la duplicación "masculino/femenino" sino lo que llama un "lenguaje inclusivo" que, rompiendo el binarismo de la oposición gramatical de "masculino/ femenino" exprese todas las diversas variedades de identidad sexual: LGBTQ+ (lesbianas, gays, bisexuales, transexuales, queer y más...). Habría así una serie de identidades de sexo que reclaman también su espacio de visibilidad en el discurso público.

Desde esta perspectiva, ya no se trata solamente de la repetición sistemática del discurso en términos de "masculino y femenino": "los obreros / las obreras", sino que deberá repetirse tal o cual segmento discursivo de- 
clinado en dos o tres o cuatro veces según cuántas "identidades de género" se quieran distinguir. No se podrá por lo tanto decir algo como "Todos los hijos están invitados", sino "Todos, todas, todes/ los, las, les/ hijos, hijas, hijes/ están invitados, invitadas, invitades... etc.

Para cualquier hablante de una lengua, esta exigencia genera un tipo de comunicación que se torna imposible. Desde el punto de vista lingüístico, llegamos así a un caso, extremo, que choca por lo menos con dos aspectos fundamentales del lenguaje humano: la categorización de la realidad y el carácter continuo del discurso y su organización textual. Veamos, para empezar, el primer aspecto.

\section{La categorización de la realidad}

El lenguaje puede ser considerado como la más grande creación del ser humano, tanto que se estima que marca una etapa fundamental en el proceso multisecular de la hominización. Homo loquens se ha podido decir: "el hombre es un animal que habla", porque esta capacidad lo separa radicalmente de todo el resto del reino animal. Y quizá sea útil para nuestra discusión señalar que todas las lenguas han sido construidas sobre las mismas bases:

a) Todas tienen un carácter sonoro, duplicado posteriormente por el carácter visual, con la invención de la escritura. Toda modificación tiene que respetar estas dos características: la grafía y la pronunciación.

b) Todas resultan de la capacidad mental de establecer categorías (divisiones categoriales) en el infinito de la realidad. Se habla así de la capacidad humana de construir "una gramática" de la realidad.

c) Todas resultan de una actividad social. "El lenguaje nunca fue inventado por un sujeto solo en su aprehensión del mundo externo" (Maturana y Varela, 1984, p. 155).

Para la discusión que nos ocupa, nos detendremos en el segundo punto: la capacidad humana de categorizar "los objetos del mundo real". Cuando decimos por ejemplo "árbol" no estamos designando un objeto específico, sino todos aquellos que englobamos mentalmente en la categoría "árbol".

Borges (1989) nos relata, en un texto magnífico de Ficciones ("Funes el memorioso"), que:

Locke, en el siglo XVII, postuló y (reprobó) un idioma imposible en el que cada cosa individual, cada piedra, cada pájaro tuviera un nombre propio (...) [Y nos cuenta que su amigo Funes iba más allá]. No solo 
le costaba comprender que el símbolo genérico "perro" abarcara tantos individuos dispares de diversos tamaños y de diversa forma; le molestaba que el perro de las tres y catorce (visto de perfil) tuviera el mismo nombre que el perro de las tres y cuarto (visto de frente). (p. 490)

Como nos dice la ciencia lingüística, no puede haber lenguaje sin la capacidad de reducir los objetos "de la realidad" a categorías semánticas (llamadas palabras) que engloban una cantidad infinita de individuos en una sola denominación verbal. Si eso ocurre con la capacidad de "denominación" (nombrar las cosas), el mismo fenómeno mental se aplica a las "categorías gramaticales": número, género (para las categorías nominales); tiempo, modo, finito/no finito, etc. (para las categorías verbales).

Por ello, queda fuera de la lógica de cualquier lengua humana el tratar de dividir la categoría de género en todo el número de posibilidades en que pueda declinarse "la diversidad sexual". Y, una vez más, conviene insistir en que el problema de la discriminación que puede darse contra determinadas minorías sexuales está afincado en la realidad social y no en el lenguaje.

Otra característica de la comunicación humana es la continuidad del discurso. Los seres humanos no hablamos con palabras aisladas, como lo hace el mítico hombre de la selva: "Yo Tarzán, tú Jane." Hablamos con frases que se van uniendo para formar un texto completo. Y este tejido textual se va construyendo según las reglas de progresión y cohesión/coherencia textual (Álvarez, 2002). En lo esencial, cada nuevo segmento textual que se va agregando debe conservar las informaciones gramaticales que están contenidas en los segmentos ya producidos. Supongamos una vez más que el hablante ha comenzado su texto con: "Los las les/ hijos hijas hijes/ están todos todas todes/ invitados invitadas invitades". A esta primera frase habría que agregarle todas las frases similares que siguen hasta completar el texto. ¡Solo "Funes el memorioso" podría comunicar con una lengua así! En la realidad, parece ser que los hablantes, o escribientes, de ese "lenguaje inclusivo" solo utilizan esa pluralidad de marcas de vez en cuando, sobre todo al empezar, y luego prosiguen "en lengua natural". Conviene dejar constancia aquí que han surgido otras tentativas de "lenguaje inclusivo" como la de escribir todo el texto en "e" haciendo desaparecer las marcas de género existentes (o / a): Todes les niñes están invitades. Se evita así la fatigosa repetición, pero el problema lingüístico persiste. También se debe dar cuenta de tentativas con el mismo objetivo -borrar las marcas de género- utilizando caracteres tipográficos imposibles de pronunciar, porque no tienen carácter vocálico: amig@s, todxs, etc. Todas estas tentativas apuntan en el fondo a eliminar las marcas específicas de género (o/a y otras) crean- 
do y utilizando solo una forma neutra (lo que parece ser contrario a lo que buscaba al menos una parte del movimiento feminista, que era dar mayor visibilidad a la mujer en el ámbito del discurso).

Numerosos lingüistas y profesores de lengua han elevado sus voces para señalar que esa forma de hablar o de escribir da origen a unas construcciones verbales absurdas, imposibles de pronunciar, de un nivel de redundancia tal que alargan cualquier texto de tal manera que toda comunicación se hace imposible. Agréguese que la obsesión por la feminización llega a un nivel que se extiende incluso a referentes "no sexuables", como "sujeto", "cuerpo", etc. Así, una mujer es "una sujeta política", y el grupo en que participa no es un colectivo, sino "una colectiva", y no tiene un cuerpo sino "una cuerpa".

En septiembre pasado (2020) un grupo de 32 lingüistas de diversas universidades de Europa firmaron una declaración en la que afirman que el llamado "lenguaje inclusivo", en los hechos, excluye a sus practicantes del resto de su comunidad lingüística. Estos académicos critican la variedad francesa que ha tomado el "lenguaje inclusivo" que, para evitar la interminable repetición de las palabras, utilizan una escritura en la que cada palabra se rompe en tres o cuatro partes separadas por un punto. Así en vez de "Tous/toutes les travailleurs/travailleuses", se debe escribir: "Tou.t.e.s les travailleu.r.se.s". Dicen bien "escribir" porque esas secuencias son impronunciables. Hay que imaginar lo que representaría la lectura, en silencio o en voz alta, de un texto normal de 10 o 15 páginas escrito en este extraño lenguaje (Authier-Revuz, 2020).

Este supuesto "lenguaje inclusivo" en la realidad es excluyente, porque aísla a sus "hablantes" del resto de su comunidad lingüística. No se debe olvidar que la comunicación circula entre dos polos: un emisor (o sujeto comunicante) y un receptor (destinatario / sujeto interpretante), y que para poder comunicar, ambos tienen que utilizar un lenguaje que los una, los enlace, los interprete, a los dos. Sin este "compartir la lengua" no hay comunicación posible.

\section{El cambio lingüístico}

En estas discusiones, el lingüista -estudioso de la ciencia del lenguaje- es percibido a veces como un ser retrógrado que defiende el statu quo y que se opone a todo cambio. Lo que es totalmente absurdo. Examinemos este malentendido.

Una de las nociones básicas de la ciencia lingüística es aquella que afirma que el lenguaje está en permanente cambio. Pero la dinámica, la veloci- 
dad, de estos cambios es muy diferente según los diversos componentes del lenguaje. Así podemos señalar que:

a) La escritura puede cambiar con mucha facilidad, porque es un componente externo al lenguaje mismo. De hecho, la invención de la escritura data de poco más de cinco siglos. Antes de ello, por más de trescientos mil años las lenguas fueron solamente orales.

b) De los componentes propiamente lingüísticos, el sistema lexical es el que cambia más rápidamente. Nuevas palabras se crean en forma permanente. En algunos casos, un vasto conjunto de cambios lexicales puede producirse de una generación a otra, como es el caso actual de la introducción masiva de los términos de la informática.

c) El sistema propiamente gramatical (morfología y sintaxis) constituye el núcleo duro de la lengua. Comprende todas las categorías gramaticales como género, número, tiempo, modo, etc. Y esta es la parte más resistente de la lengua. Un cambio en estas distinciones categoriales puede demorar 10 o 15 siglos, como ya lo mencionamos con la desaparición de la forma neutra del latín clásico.

Exigir "el abandono de las categorías binarias" (femenino/masculino) aparece entonces como una propuesta irrealizable. Recordemos que la lengua es una construcción social: ningún individuo ni grupo de individuos es dueño de la lengua; ningún individuo o grupo de individuos aislado puede crear una nueva categoría gramatical.

\section{A MODO DE CONCLUSIÓN (SIEMPRE PROVISORIA)}

El mundo occidental se encuentra en un período de transición, de una cultura "machista" "patriarcal", en la que el hombre poseía el control no solo del lenguaje sino de toda la vida de "la familia" (él era "el jefe de familia", administrador del patrimonio familiar) a una cultura en la que el hombre y la mujer negocian entre ambos la vida de la familia. Algo similar ocurre en la participación en el espacio público. La mujer reclama y va obteniendo cada vez más su debido lugar tanto en el espacio privado como en el espacio público, y una nueva repartición del poder. Un fenómeno social-culturaleconómico-simbólico que sin duda redunda en un enriquecimiento de la democracia y de la cultura humana.

En este tránsito de un modo de vida patriarcal y autoritario a un mundo igualitario y solidario, se van presentando sin duda conflictos y desacuerdos que se deben ir resolviendo por la discusión y la práctica de la nego- 
ciación entre iguales. Negociación de tareas, funciones, poderes y representaciones compartidas ( ${ }_{i}$ Por qué no existe un salario para las tareas de la reproducción? ¿Por qué de todas las universidades públicas que existen en el país, ninguna está dirigida por una rectora electa?); negociación de las modificaciones necesarias en el lenguaje: palabras, formas de comunicación, ocupación y control del espacio discursivo. (¿Por qué se socializa a los niños como activos y enérgicos, con derecho a la palabra, y a las niñas como comprensivas, pasivas y empáticas? (ver la noción de curriculum oculto en Estrada, 2004) ¿Por qué los hombres piensan que ellos tienen el derecho a intervenir en el espacio personal de las mujeres, tocándolas o rozándolas, o lanzándoles "un piropo" en la calle?).

El movimiento feminista constituye uno de los más grandes fenómenos civilizatorios del último tiempo. Un movimiento que está impulsando la construcción de un mundo más democrático, más justo, en el que todos los seres humanos tengan cabida y sean respetados independientemente de su sexo (o su orientación sexual), de su raza o de su clase social. Los excesos que se están cometiendo en estos momentos -especialmente en materia de lenguaje- tendrán que irse corrigiendo, para hacer verdad aquello que decía el poeta Louis Aragon: "la mujer es el porvenir del hombre". O dicho en términos más políticos, "el futuro de la Humanidad viene de la mano de las mujeres".

\section{REFERENCIAS}

Álvarez, A. y Vilches, H. (2019). Desigualdad jurídica, exclusiones étnicas, y derecho de sufragio. Estudio normativo y socio-cultural con mujeres aymaras de Tarapacá, Chile. Interciencia 44(3), 131-139.

Álvarez, G. (2002). Textos y discursos. Introducción a la lingüística textual. Concepción: Editorial Universidad de Concepción.

Authier-Revuz, J. (2020). Une «écriture excluante» qui «s'impose par la propagande»: 32 linguistes listent les défauts de lécriture inclusive, editado por Tribune collective https://www.marianne.net/agora/tribunes-libres/uneecriture-excluante-qui-s-impose-par-la-propagande-

Baros, M. C. (2020, marzo). Mujeres pioneras en ingeniería y minería. Boletín minero, 1337, 19-22.

Borges, J.L. (1989). Obras completas. Tomo I. Barcelona: Emecé editores.

Cano, G. (1990). Declaración de los derechos de la mujer y la ciudadana. Iztapalapa, Revista de Ciencias Sociales y Humanidades 19, 77-80.

Estrada, A. M. (2004). Dispositivos y ejecuciones de género en escenarios escolares, en C. Millán y A. M. Estrada (eds.). Pensar (en) género. Teoría y 
práctica para nuevas cartografías del cuerpo (pp. 18-49). Bogotá: Pontificia Universidad Javierana.

Hobsbawn, E. (2006). La era de la revolución 1789-1848. Buenos Aires: Crítica. Labrune G. et Toutain, Ph. (1986). L'Histoire de France. Paris: Éditions Nathan. López Varas, MA. y Gamboa Valenzuela, R. (2015). Sufragio femenino en Chile: origen, brecha de género y estabilidad, 1935-2009. Revista de Estudios Sociales 53, 124-137. http://journals.openedition.org/revestudsoc/9349

Maturana, H. y Varela F. (1984). El árbol del conocimiento. Santiago: Editorial Universitaria.

Pottier, B. (1974). Linguistique générale. Paris: PUF.

Ruiz, J. (Arcipreste de Hita) (1992). Libro de Buen Amor, edición de Alberto Blecua. Madrid: Cátedra.

Salas, G., Scholten, H., Guerra-Labbé, L., Ramos-Vera, J., Pardo-González, E. (2019). Eloísa Díaz Insunza: entre la medicina, la psicología y la educación. Revista Médica de Chile 147(4), 499-504.

Saussure, F. (1916). Cours de lingüistique générale. Paris: Payot. 